Published in final edited form as:

Prev Med. 2017 November ; 104: 31-36. doi:10.1016/j.ypmed.2017.06.034.

\title{
The Potential Impact of Cannabis Legalization on the Development of Cannabis Use Disorders
}

\author{
Alan J. Budney ${ }^{1}$ and Jacob T. Borodovsky ${ }^{1,2}$ \\ ${ }^{1}$ Geisel School of Medicine at Dartmouth, Center for Technology and Behavioral Health, 46 \\ Centerra Parkway, Lebanon, NH 03766, United States \\ ${ }^{2}$ The Dartmouth Institute for Health Policy and Clinical Practice, 74 College St. Hanover, NH \\ 03755, United States
}

\begin{abstract}
Specific provisions of legal cannabis legislation and regulation could influence cannabis initiation, frequency and quantity of use, and progression to cannabis use disorder. This brief essay highlights scientifically based principles and risk factors that underlie substance use and addiction that can be leveraged to inform policies that might mitigate the development and consequences of cannabis use disorder. Specifically, pharmacologic, access/availability, and environmental factors are discussed in relation to their influence on substance use disorders to illustrate how regulatory provisions can differentially affect these factors and risk for addiction. Relevant knowledge from research and experience with alcohol and tobacco regulation are also considered. Research designed to inform regulatory policy and to evaluate the impact of cannabis legislation on cannabis use and problems is progressing. However, definitive findings will come slowly, and more concerted efforts and resources are needed to expedite this process. In the meantime, policymakers should take advantage of the large body of scientific literature on substance use to foster empirically-guided, common sense approaches to cannabis policy that focus on prevention of addiction.
\end{abstract}

Cannabis use has been linked to multiple short-term and long-term consequences including impairment in short-term memory, motor coordination, altered judgment, acute paranoia or psychosis and risk of chronic psychotic disorders, altered brain development, poor educational and vocational outcomes, and the development of cannabis addiction (Hall, 2009; Volkow et al., 2014). The majority of Americans currently support some form of cannabis legalization, and over half of U.S. states have enacted laws permitting the use of cannabis for medical and recreational purposes (Legal Cannabis Laws, LCLs) recognizing the potential for positive consequences of such policies (Geiger, 2016; ProCon.org, 2017).

Corresponding Author: Alan J. Budney, Alan.J.Budney@dartmouth.edu, Dartmouth Geisel School of Medicine, Center for Technology and Behavioral Health, 46 Centerra Parkway, Lebanon, NH 03766, United States.

Publisher's Disclaimer: This is a PDF file of an unedited manuscript that has been accepted for publication. As a service to our customers we are providing this early version of the manuscript. The manuscript will undergo copyediting, typesetting, and review of the resulting proof before it is published in its final citable form. Please note that during the production process errors may be discovered which could affect the content, and all legal disclaimers that apply to the journal pertain.

Conflict of Interest Statement: The authors declare no conflict of interest other than the receipt of research funding support from the NIH-NIDA as indicated above 
However, there is increasing societal concern that these laws may impact the prevalence and severity of the potential adverse effects of cannabis use. A critical issue, and the focus of this essay, is how LCLs may affect the prevalence of one of these consequences, the development of cannabis use disorder (CUD) or "addiction".

CUD, like other substance use disorders, consists of a constellation of biopsychosocial impairments engendered by frequent and heavy cannabis use (Budney, 2006; Hasin et al., 2013). Concern about the proliferation of CUD warrants careful consideration because CUD has been associated with problems in multiple domains of psychosocial functioning (Colliver et al., 2006; Hasin et al., 2015), and rates of CUD increased in the U.S. over the past 10-15 years, particularly in LCL states (Hasin et al., 2015; Hasin et al., 2017; Wen et al., 2015). Understanding how LCLs impact patterns of cannabis initiation and use among youth is particularly important to understand given this population's neurobiological and psychosocial vulnerabilities. Earlier initiation of cannabis use exposes youth to greater risk for developing CUD as well as poor educational and vocational achievement, and increased mental health problems during adolescence and adulthood (C. Y. Chen et al., 2009; King and Chassin, 2007; Lopez-Quintero et al., 2011; Volkow et al., 2014).

LCLs comprise multiple specific provisions that detail regulatory processes for determining how cannabis products can be created, distributed, and accessed. Some of these provisions have the potential to influence rates of cannabis initiation, frequency and quantity of use, and ultimately, progression to CUD. The current legislative process in the U.S. involves each state crafting its own unique model of cannabis legalization. This has resulted in highly diverse models each with potential for differential impact on the development of CUD. In order to understand how specific provisions within these models may impact development of CUD, one must first recognize and consider the factors known to influence substance use and development of problematic patterns of use. The etiology of CUD (as with all substance use disorders) is related to a collection of risk factors (McCrady and Epstein, 2013), and consideration of the impact of LCLs on addiction must keep in mind the interactions among such influences. This essay seeks to elucidate how LCLs may influence or interact with pharmacological, behavioral, biological, and sociocultural risk factors that determine the probability of developing a CUD by using data gleaned from behavioral and clinical pharmacology, neurobiology, behavior analysis, behavioral economics, and epidemiology. By identifying and clarifying these relationships, we hope this existing knowledge base will be used to guide policy, and to anticipate, mitigate, and prepare for the consequences of LCL enactment on the development of CUD. We will examine three "risk factor" areas: pharmacology of drug effects, access/availability of substances, and environmental influences.

\section{Pharmacology}

Substances, including cannabis, that are used recreationally and which pose a risk for the development of a clinical substance use disorder ("addiction") are attractive to most humans because they function as reinforcers (Higgins et al., 2004). That is, the experience that immediately follows drug taking is desirable, and therefore the drug is likely to be used again. The strength of such a reward or reinforcement is determined by multiple factors, the 
most obvious of which is the direct effects of the substance on the central nervous system and the subsequent pleasurable or desirable experience.

Two elements that influence the direct effects of substance use are the dose or potency of the drug consumed and the method or route of administration by which it is used. The direct positive reinforcing effects of the primary psychoactive component of cannabis, delta-9tetrahydrocannabinol (THC), are mediated by cannabinoid receptor (CB1) via activation of the mesolimbic dopamine system, the brain's reward system (Cooper and Haney, 2009). Higher potency (greater \% THC) cannabis generally engenders more desirable or rewarding effects than lower potency cannabis. Users therefore, generally prefer and are more likely to repeatedly self-administer higher potency cannabis (Chait and Perry, 1994; Cooper and Haney, 2009). This putatively increases risk associated with higher THC potency. However, such risk might be counterbalanced partially by users' self-titrating the amount they consume. The effects of self-titration have not been well studied and the literature on its effects is equivocal (Ramesh et al., 2013; van der Pol et al., 2014; van der Pol et al., 2013).

In combination with dose/potency, how one uses cannabis (i.e., smoke, eat, vaporize) contributes to the magnitude of intoxication and subjective qualities of the experience. Smoking delivers THC to the central nervous system much more quickly than oral ingestion, leading to a more rapid onset of effects, and in some cases a more intense experience (Vandrey et al., 2017). Smoking cannabis, however, involves ingestion of noxious smoke, which produces potentially negative or undesirable sensations, and delivers known carcinogens into the body (Tashkin et al., 2002). Vaporizing or vaping cannabis, an increasingly popular method of cannabis use (Budney et al., 2015), reduces these potentially negative aspects of smoking, while providing a rapid onset of desirable effects comparable to the effects from smoking (Abrams et al., 2007). In summary, higher dose THC and the availability of desirable methods to deliver THC rapidly to the brain can be considered risk factors for repeated cannabis use and development of CUD.

So why are these pharmacological effects relevant to cannabis legislation's potential impact on problem development? As cannabis legislation has spread across the U.S., the potency of cannabis products available for sale in medical and recreational dispensaries generally dwarfs that previously available through illegal markets (Carlini et al., 2017; ElSohly et al., 2016; Vandrey et al., 2015). New types of cannabis extracts have been documented to have THC concentrations of up to $75 \%$ (Raber et al., 2015). These high THC concentrated products are designed for use via vaping or smoking, or are sold as highly palatable edible products (e.g., chocolate bars, sodas, chewable candies, cookies, etc.). Moreover, vaping devices are many times sold alongside these products and are now available in an increasing number of vape shops that also sell flavored nicotine for use in electronic cigarette devices. Increases in product potency and diversity appear related to the presence of for-profit cannabis dispensaries (retail stores) that are motivated to increase sales (Borodovsky et al., 2016; Pacula et al., 2014b; Richter and Levy, 2014; Sevigny et al., 2014). Production and availability of high-potency cannabis may also be inadvertently exacerbated by taxation structures based on the weight of cannabis, which creates an incentive for manufacturers to develop low-weight, high-THC content products (Hall and Lynskey, 2016). 
Such changes in the landscape of cannabis products and methods of use could impact cannabis initiation, repeated cannabis use, and the development of use disorders in multiple ways. First, higher potency products increase the probability of experiencing desirable effects in first-time users and require less ingestion of noxious smoke when using combustible methods. This putatively produces a more pleasurable first experience with cannabis and an increased likelihood of repeated use. Similarly, vaping or edible use of cannabis would avoid the need to ingest toxic smoke, and thereby increase the chances of trying cannabis for the first time and experiencing desirable effects. A more positive first experience combined with availability of highly palatable (edibles) and high potency products that do not require smoking might to facilitate an easier path to escalating and problematic cannabis use patterns (Agrawal et al., 2013; Fergusson et al., 2003). Youth that use vaping devices, report using extract preparations of cannabis with high THC content (Morean et al., 2015). Consequently vaping, particularly of high potency cannabis, may increase the development of tolerance and the likelihood of withdrawal - two factors that contribute to the development of a use disorder (Loflin and Earleywine, 2014).

Clearly, specific provisions of cannabis policies and regulations can impact availability and use of high potency cannabis products or devices. For example, many current state cannabis laws stipulate possession amounts per individual (which vary substantially across states). These statutes have recently begun to address potency (THC content) of permitted cannabis products (Healthy Colorado Coalition, 2016). Recent California cannabis legislation (Proposition 64) has recognized these issues, listing cannabis potency as one of its statefunded research initiatives, asserting the state's authority to impose scientifically appropriate limits on potency levels (State of California, 2016). A few states have also limited use of cannabis to specific routes of administration (e.g. NY and MN do not allow smoking of cannabis).

The importance of imposing regulations on the content of psychoactive compounds in alcohol and tobacco products to effectively impact intoxication and development of addiction, has long been recognized, as has concern about product additives that may increase their addictive potential (Henningfield et al., 2004; Mosher and Johnsson, 2005). Indeed, the NIH and FDA have recently devoted substantial effort and funds to continue scientific inquiry about how best to regulate nicotine content and nicotine delivery devices to mitigate the development of addiction and limit other adverse effects of tobacco and nicotine use (Printz, 2014). Similar steps are clearly needed to guide regulatory efforts related to cannabis product potency and how such products are consumed.

\section{Access/Availability}

The ease or difficulty of accessing an intoxicating substance has an obvious, but often underestimated, influence on individual and population-level substance use initiation, frequency and amount of use, and consequently the risk of developing a substance use disorder. Behavioral economics provides a multi-dimensional conceptualization of access or availability of a reinforcer (e.g., cannabis) that can help one appreciate its potential impact on use and addiction (Bickel et al., 2014; Hursh and Roma, 2013). The organizing construct of "unit price" describes how consumption is determined by the cost of the product divided 
by the magnitude of reward or reinforcement derived from the product, and the unit price of other products that are concurrently available. Most importantly, in this model, cost includes not only monetary price, but also the amount of effort and time required to obtain the product.

Accordingly, the mechanisms of access to cannabis dictated by LCLs can impact populationlevels of use and the development of use disorders. For example, currently many states provide access to cannabis through licensed dispensaries (Pacula et al., 2014a). Some laws permit only a few dispensaries (Connecticut Department of Consumer Protection, 2016) while others permit hundreds (Colorado Department of Revenue, 2016). Greater numbers of places to purchase a product translates to lower cost (less travel time, lower transportation cost). Studies of alcohol and tobacco retail outlet density and residential proximity to outlets indicate a positive relationship with the initiation of use, heavier and more problematic use, and more difficulty quitting use (Cantrell et al., 2016; M. J. Chen et al., 2009; Kuntsche et al., 2008; Pacula et al., 2014b; Reitzel et al., 2011; Scribner et al., 2000). Similar relationships have emerged in the nascent cannabis literature. For example, states with medical cannabis laws that legally protect dispensaries have more adult and youth cannabis use treatment admissions than medical cannabis states that do not legally protect dispensaries (Pacula et al., 2015). More cannabis dispensaries per square mile also predicts more frequent cannabis use (Freisthler and Gruenewald, 2014), and higher CUD-related hospitalizations (Mair et al., 2015). Last, a greater number of dispensaries per capita predicts cannabis use and a younger age of initiation of vaping and edible products (Borodovsky et al., 2016; Borodovsky et al., 2017).

Another provision of many state LCLs related to access is whether or not individuals are permitted to grow cannabis, i.e., home cultivation (Pacula et al., 2014a). Home cultivation presents challenges for preventing the excessive growth of cannabis and its diversion. Home cultivation may provide youth with easier access to cannabis, lower the age of first cannabis use, and increase the risk of developing a use disorder (Caulkins et al., 2012; Pacula et al., 2015). Between 1992 and 2011, over 85\% of treatment admissions for CUD that occurred in states with medical cannabis laws, occurred in states that permitted home cultivation (Pacula et al., 2015). Home cultivation also predicts past month use and heavy use ( $\geq 20$ day) (Pacula et al., 2015). It may also be associated with higher likelihood and younger age of onset of cannabis edible use (Borodovsky et al., 2017).

Last, state legislation can impact monetary price of cannabis. Economic projections of the price of cannabis associated with the proliferation of legalization clearly indicate substantial decreases compared to pre-legalization cost (Caulkins et al., 2012; Hall and Lynskey, 2016). Leveraging the clear and consistent negative relationship between monetary price and consumption of tobacco and alcohol products is a staple public health strategy for mitigating population-level use and harm associated with those substances (Chaloupka et al., 2002; Chaloupka et al., 2010; Farrell et al., 2003; Pacula et al., 2014b). Each state that legalizes the distribution and sale of cannabis will need to determine tax rates at the manufacturing, sales, and purchase levels. Keeping prices at a level that helps control excessive use through strategic and nuanced taxation policies would seem reasonable. However, enacting effective taxation policy is challenging, as much remains unknown about this nascent industry, and 
increased tax revenue must be balanced against the behavior of black markets in response to such policies (Caulkins et al., 2012). Of note, price may differentially impact frequency of use and the development of use disorders among various cannabis user subgroups (Pacula and Lundberg, 2014). How to use taxation to most effectively mitigate the prevalence and incidence of excessive use, adverse effects, and use disorders in the population will require careful thought and additional study.

\section{Environmental Factors}

Multiple aspects of the environment or context in which substances are available (e.g., neighborhood socioeconomic status,, cultural factors, societal norms and laws, marketing and advertising) exert an impact on the age of onset, probability, frequency, and amount of use, and problem development (Bickel and DeGrandpre, 1996). Here we briefly discuss just two such factors that are particularly susceptible to the influence of legislation and regulations_-marketing and social norms regarding the perception of risk.

Exposure to commercial advertisement and promotion, portrayal of use (modeling) in entertainment media, point of sale advertising, and packaging have all been identified as "effective" marketing strategies that influence tobacco and alcohol initiation and rates of consumption (Anderson et al., 2009; Kollath-Cattano et al., 2016; Lovato et al., 2011). In response to these observations, government agencies and industry regulatory boards have either prohibited or made strong recommendations limiting the advertising and marketing of these substances. These licit substance industries have long known that heavy alcohol and tobacco users in the population generate the majority of profits (Chaloupka et al., 2002; Cook et al., 2002). The same may potentially be true for the emerging cannabis industry (Caulkins et al., 2015; Kilmer, 2014). This dynamic incentivizes companies to maximize profits by creating and sustaining heavy users of their products. This begins with marketing strategies that encourage initiation and continuation of use through shaping of productrelated attitudes, beliefs, and expectations, and the normalizing of use (DiFranza et al., 2006; Landman et al., 2008; Pechmann and Knight, 2002). Adolescents are particularly susceptible and appealing targets for such strategies because earlier age of onset of use is associated with increased risk for later heavy tobacco, alcohol and cannabis use, and for alcohol and cannabis use use disorders (Agrawal et al., 2006; Biener and Siegel, 2000; Chen et al., 2005; David J. DeWit et al., 2000; Evans et al., 1995; Perkonigg et al., 2008; Swift et al., 2008). As might be predicted based on the alcohol and tobacco literature, data connecting cannabis advertising and age of onset are beginning to emerge (D'Amico et al., 2015; Roditis et al., 2016; Schuermeyer et al., 2014).

To date, state restrictions on cannabis marketing through advertising on TV, radio, billboards, or social media, or by sponsorship at cultural and sports events, have not aggressively addressed this risk factor (Barry and Glantz, 2016). If not constrained, there is little reason to expect that the rapidly expanding cannabis industry will self-regulate their marketing to decrease heavy cannabis use and CUD among vulnerable groups (Barry and Glantz, 2016; Caulkins et al., 2016; Kilmer, 2014; Pacula et al., 2014b; Richter and Levy, 2014). Policymakers at local, state, and federal levels can readily leverage knowledge of effective approaches to marketing and advertising gleaned from many years of research and 
practice in the tobacco and alcohol fields to preemptively mitigate their impact on the proliferation of cannabis use and problem development.

Cannabis legalization, whether medical or recreational, may affect social norms and perceptions of the risks from use cannabis use. Decades of epidemiological data from the U.S. demonstrate a negative relationship between prevalence of cannabis use and perceived risk of harmfulness (Johnston et al., 2015). Of concern, the perceived risk of cannabis has declined substantially over the past two decades (Keyes et al., 2016; Pacek et al., 2015), and this has been accompanied by a parallel increase in the overall prevalence of cannabis use and the prevalence of CUD (Hasin et al., 2015). However, the literature on the relation between cannabis legalization and perceptions of risk to date has been equivocal. (Keyes et al., 2016; Miech et al., 2015; Schmidt et al., 2016; Schuermeyer et al., 2014; Wall et al., 2011). It is possible that a reciprocal relationship exists between cannabis risk perception and LCL enactment. For example, States with a pre-existing liberal cannabis culture may be more likely to enact LCLs, and those LCLs may subsequently reinforce the liberal cannabis culture. The mechanisms by which cannabis legalization can influence norms and perceptions are many.

Removing legal risks can impact population-level cannabis use by restructuring economic demand and changing patterns of use over time (Pacula and Lundberg, 2014). Enactment of medical cannabis laws has been tied to a significant portion of high school students indicating that they would either try cannabis or use more cannabis if it became legal in their state (Palamar et al., 2014). However, other studies have not demonstrated robust relationships among cannabis legalization, risk perception, and use (Harper et al., 2012).

In 2014, states with medical cannabis laws averaged more than 13 medical conditions that could qualify individuals for use of cannabis, and the number of conditions continues to escalate. Such conditions include most any type of pain, diverse neurological disorders like Alzheimer's, epilepsy and ALS, simple nausea and disorders for which nausea or cachexia is part of the syndrome or treatment such as HIV/AIDS or cancer, disorders that involve muscle spasticity, and psychiatric disorders like PTSD (Bestrashniy and Winters, 2015). How this ubiquitous list of medical conditions for which states have deemed cannabis an effective treatment impacts public perception of the harmfulness, risk, and health-related beliefs associated with cannabis is not known, yet one can readily surmise with some confidence that it would reduce perceived concerns about the potential harms related to cannabis use. Moreover, when retail cannabis dispensaries outnumber Starbucks or McDonalds in a geographic area, as is the case in Colorado, the influence on social norms and access to cannabis could be substantial (Pacula et al., 2015; Rocky Mountain High Intensity Drug Trafficking Area, 2016).

Some legislative provisions could help curb normalization of cannabis use and the observed declines in cannabis use risk perception. Similar to bans on use of tobacco in public places (Komro et al., 2013), bans on use of cannabis in public may influence public attitudes and social acceptability of cannabis use. Fortunately, most states with active cannabis laws have banned use of cannabis in public. Other regulatory targets to consider include: clear and strict limits on advertising and marketing, a reduction in the number and visibility of 
dispensaries, restrictions on home cultivation, and restricting or eliminating state-approved use of cannabis for medical disorders (Barry and Glantz, 2016; Pacula et al., 2014b). This last target, the state-sanctioned medical use of cannabis, although the most controversial, warrants careful consideration especially if the goal is to seriously address trends toward normalization and the reduction in perception of a potential for harm. Adequate evidence is sorely lacking for the clinical efficacy of cannabis or cannabinoids for the great majority of maladies currently approved (Belendiuk et al., 2015; D'Souza and Ranganathan, 2015; Whiting et al., 2015). Consequently, eliminating state approval for self-medicating this plethora of conditions with a substance that has substantial potential for misuse and addiction would seem rational. Taking action in this direction would more clearly align cannabis with the other common licit substances, alcohol, and tobacco, and perhaps facilitate more effective preventive educational programs. Which leads to a final legislative provision worthy of mention, the funding of mandatory prevention and intervention programs and research in the area of cannabis regulatory science funded with tax dollars from cannabis licensing and sales. A number of states already have included such provisions and research is underway (Skinner et al., 2016). The success of such funding mandates is not yet clear, but similar efforts have proven successful for alcohol and tobacco use prevention.

\section{Concluding Comments}

States across the U.S. are attempting to achieve a difficult legislative goal - the regulation of legal cannabis without increasing the prevalence of problematic cannabis use and CUD. Such efforts can benefit from a comprehensive working knowledge of the multiple factors that influence addiction. In this brief essay, we have identified a few well-established risk factors, based on research from multiple scientific disciplines, and attempted to illustrate how specific provisions of cannabis laws and regulations may impact these factors and thereby prevent or exacerbate the risk of addiction.

Direct study of the impact of legislation enacted to date is underway, however, the continuously changing legislative and regulatory environment across and within states makes this a most challenging endeavor (Pacula and Sevigny, 2014). Much is also yet to be learned about novel, high potency cannabis products and alternative methods for using cannabis that are readily available and commonly used. Research in this area progresses, but has been slowed by statutes in the Federal Controlled Substances Act and Food and Drug Administration policies designed to protect public health. Federal guidance and funding that can enhance and expedite research efforts in these areas are sorely needed, and there exist some indications that this may be on the horizon. The National Institute on Drug Abuse, the National Center on Complementary Medicine and Integrative Health, and the National Institute of Neurological Disorders and Stroke of the NIH have taken substantial steps towards funding basic and clinic research in this area (National Institutes of Health, 2016).

Until new data emerge to guide policy, existing basic and clinical science on addiction in general, and cannabis use and problem development in particular, can be used to effectively inform policy decisions. Moreover, because cannabis can be considered highly similar to the other commonly used substances that have addictive potential, experience with alcohol and tobacco regulation can provide informed guidance on the impact of specific regulatory 
provisions on cannabis use and CUD (Budney, 2007; Budney and Lile, 2009; Vandrey and Budney, 2015). Enacting LCLs may have multiple negative and positive public health and cultural consequences. We hope that this brief essay calls attention to the large body of scientific evidence that can inform empirically guided, common sense approaches to cannabis policy that will focus on the prevention of addiction (Weiss et al., 2017).

\title{
Acknowledgments
}

\author{
NIDA: R01-DA032243, T32-DA037202, P30-DA029926
}

The funding sources were not involved in the study design; collection, analysis, and interpretation of data; writing of the report; or in the decision to submit the article for publication.

\section{References}

Abrams DI, Vizoso HP, Shade SB, Jay C, Kelly ME, Benowitz NL. Vaporization as a smokeless cannabis delivery system: a pilot study. Clinical Pharmacology and Therapeutics. 2007; 82:572-8. [PubMed: 17429350]

Agrawal A, Grant JD, Waldron M, Duncan AE, Scherrer JF, Lynskey MT, Madden PA, Bucholz KK, Heath AC. Risk for initiation of substance use as a function of age of onset of cigarette, alcohol and cannabis use: findings in a midwestern female twin cohort. Prev Med. 2006; 43:125-8. [PubMed: 16697036]

Agrawal A, Madden PA, Martin NG, Lynskey MT. Do early experiences with cannabis vary in cigarette smokers? Drug Alcohol Depend. 2013; 128:255-9. [PubMed: 23010290]

Anderson P, de Bruijn A, Angus K, Gordon R, Hastings G. Impact of Alcohol Advertising and Media Exposure on Adolescent Alcohol Use: A Systematic Review of Longitudinal Studies. Alcohol and Alcoholism. 2009; 44:229-43. [PubMed: 19144976]

Barry RA, Glantz S. A public health framework for legalized retail marijuana based on the US experience: avoiding a new tobacco industry. PLoS Med. 2016; 13:e1002131. [PubMed: 27676176]

Belendiuk KA, Baldini LL, Bonn-Miller MO. Narrative review of the safety and efficacy of marijuana for the treatment of commonly state-approved medical and psychiatric disorders. Addict Sci Clin Pract. 2015; 10:10. [PubMed: 25896576]

Bestrashniy J, Winters KC. Variability in medical marijuana laws in the United States. Psychol Addict Behav. 2015; 29:639-42. [PubMed: 26415061]

Bickel, WK., DeGrandpre, RJ. Drug Policy and Human Nature. Springer; U.S.A: 1996.

Bickel WK, Johnson MW, Koffarnus MN, MacKillop J, Murphy JG. The behavioral economics of substance use disorders: reinforcement pathologies and their repair. Annu Rev Clin Psychol. 2014; 10:641-77. [PubMed: 24679180]

Biener L, Siegel M. Tobacco marketing and adolescent smoking: more support for a causal inference. Am J Public Health. 2000; 90:407-11. [PubMed: 10705860]

Borodovsky JT, Crosier BS, Lee DC, Sargent JD, Budney AJ. Smoking, vaping, eating: Is legalization impacting the way people use cannabis? Int J Drug Policy. 2016; 36:141-7. [PubMed: 26992484]

Borodovsky JT, Lee DC, Crosier BS, Gabrielli JL, Sargent JD, Budney AJ. U.S cannabis legalization and use of vaping and edible products among youth. Drug Alcohol Depend. 2017 In press.

Budney AJ. Are specific dependence criteria necessary for different substances: How can research on cannabis inform this issue? Addiction. 2006; 101:125-33. [PubMed: 16930169]

Budney AJ. Marijuana dependence and its treatment. NIDA Science \& Practice Perspectives. 2007; 4:4-16.

Budney AJ, Lile JA. Moving beyond the cannabis controversy into the world of the cannabinoids. Int Rev Psychiatry. 2009; 21:91-5. [PubMed: 19367502]

Budney AJ, Stanger C, Tilford JM, Scherer EB, Brown PC, Li Z, Li Z, Walker DD. Computer-assisted behavioral therapy and contingency management for cannabis use disorder. Psychol Addict Behav. 2015; 29:501-11. [PubMed: 25938629] 
Cantrell J, Pearson JL, Anesetti-Rothermel A, Xiao H, Kirchner TR, Vallone D. Tobacco Retail Outlet Density and Young Adult Tobacco Initiation. Nicotine Tob Res. 2016; 18:130-7. [PubMed: 25666816]

Carlini BH, Garrett SB, Harwick RM. Beyond joints and brownies: Marijuana concentrates in the legal landscape of WA State. Int J Drug Policy. 2017; 42:26-29. [PubMed: 28171805]

Caulkins, JP., Kilmer, B., Kleiman, MAR. Marijuana Legalization: What Everyone Needs to Know. 2. Oxford University Press; New York: 2016.

Caulkins, JP., Kilmer, B., Kleiman, MAR., MacCoun, R., Midgette, G., Oglesby, P., Pacula, R., Reuter, P. Options and issues regarding marijuana legalization. Santa Monica, CA: The RAND Corporation; 2015. Retrieved from http://www/.rand.org/content/dam/rand/pubs/perspectives/ PE100/PE149/RAND_PE149.pdf (Archived by WebCite® at http://www/.webcitation.org/ $6 Z 3 m o G 28 A)$.

Caulkins JP, Kilmer B, MacCoun RJ, Pacula RL, Reuter P. Design considerations for legalizing cannabis: lessons inspired by analysis of California's Proposition 19. Addiction. 2012; 107:86571. [PubMed: 21985069]

Chait LD, Perry JL. Acute and residual effects of alcohol and marijuana, alone and in combination, on mood and performance. Psychopharmacology. 1994; 15:340-49.

Chaloupka FJ, Cummings KM, Morley CP, Horan JK. Tax, price and cigarette smoking: evidence from the tobacco documents and implications for tobacco company marketing strategies. Tob Control. 2002; 11(Suppl 1):I62-72. [PubMed: 11893816]

Chaloupka FJ, Straif K, Leon ME. Effectiveness of tax and price policies in tobacco control. Tobacco Control. 2010

Chen CY, O'Brien MS, Anthony JC. Who becomes cannabis dependent soon after onset of use? Epidemiological evidence from the United States: 2000-2001. Drug and Alcohol Dependence. 2005; 79:11-22. [PubMed: 15943940]

Chen CY, Storr CL, Anthony JC. Early-onset drug use and risk for drug dependence problems. Addict Behav. 2009; 34:319-22. [PubMed: 19022584]

Chen MJ, Gruenewald PJ, Remer LG. Does alcohol outlet density affect youth access to alcohol? J Adolesc Health. 2009; 44:582-9. [PubMed: 19465323]

Colliver JD, Compton WM, Gfroerer JC, Condon T. Projecting drug use among aging baby boomers in 2020. Ann Epidemiol. 2006; 16:257-65. [PubMed: 16275134]

Colorado Department of Revenue. Licensees - Marijuana Enforcement Division. 2016

Connecticut Department of Consumer Protection. Connecticut Medical Marijuana Dispensary Facilities. 2016

Cook S, Herold K, Edidin DV, Briars R. Increasing problem solving in adolescents with type 1 diabetes: The choices diabetes program. The Diabetes Educator. 2002; 28:115-24. [PubMed: 11852741]

Cooper ZD, Haney M. Actions of delta-9-tetrahydrocannabinol in cannabis: relation to use, abuse, dependence. Int Rev Psychiatry. 2009; 21:104-12. [PubMed: 19367504]

D'Amico EJ, Miles JNV, Tucker JS. Gateway to Curiosity: Medical Marijuana Ads and Intention and Use During Middle School. Psychology of Addictive Behaviors. 2015; 29:613-19. [PubMed: 26030167]

D'Souza DC, Ranganathan M. Medical Marijuana: Is the Cart Before the Horse? JAMA. 2015; 313:2431-2. [PubMed: 26103026]

DeWit, David J., Adlaf, Edward M., Offord, David R., Ogborne, Alan C. Age at First Alcohol Use: A Risk Factor for the Development of Alcohol Disorders. American Journal of Psychiatry. 2000; 157:745-50. [PubMed: 10784467]

DiFranza JR, Wellman RJ, Sargent JD, Weitzman M, Hipple BJ, Winickoff JP, Tobacco Consortium C.f.C.H.R.o.t.A.A.o.P. Tobacco promotion and the initiation of tobacco use: assessing the evidence for causality. Pediatrics. 2006; 117:e1237-48. [PubMed: 16740823]

ElSohly MA, Mehmedic Z, Foster S, Gon C, Chandra S, Church JC. Changes in Cannabis Potency Over the Last 2 Decades (1995-2014): Analysis of Current Data in the United States. Biol Psychiatry. 2016; 79:613-9. [PubMed: 26903403] 
Evans N, Farkas A, Gilpin E, Berry C, Pierce JP. Influence of tobacco marketing and exposure to smokers on adolescent susceptibility to smoking. J Natl Cancer Inst. 1995; 87:1538-45. [PubMed: 7563188]

Farrell S, Manning WG, Finch MD. Alcohol dependence and the price of alcoholic beverages. J Health Econ. 2003; 22:117-47. [PubMed: 12564720]

Fergusson DM, Horwood LJ, Lynskey MT, Madden PA. Early reactions to cannabis predict later dependence. Archives of General Psychiatry. 2003; 60:1033-39. [PubMed: 14557149]

Freisthler B, Gruenewald PJ. Examining the relationship between the physical availability of medical marijuana and marijuana use across fifty California cities. Drug Alcohol Depend. 2014; 143:24450. [PubMed: 25156224]

Geiger, A. Support for Marijuana Legalization Continues to Rise. Pew Research Center; 2016.

Hall W. The adverse health effects of cannabis use: what are they, and what are their implications for policy? Int J Drug Policy. 2009; 20:458-66. [PubMed: 19362460]

Hall W, Lynskey M. Evaluating the public health impacts of legalizing recreational cannabis use in the United States. Addiction. 2016; 111:1764-73. [PubMed: 27082374]

Harper S, Strumpf EC, Kaufman JS. Do medical marijuana laws increase marijuana use? Replication study and extension. Ann Epidemiol. 2012; 22:207-12. [PubMed: 22285867]

Hasin DS, O'Brien CP, Auriacombe M, Borges G, Bucholz K, Budney A, Compton WM, Crowley T, Ling W, et al. DSM-5 criteria for substance use disorders: recommendations and rationale. Am J Psychiatry. 2013; 170:834-51. [PubMed: 23903334]

Hasin DS, Saha TD, Kerridge BT, Goldstein RB, Chou SP, Zhang H, Jung J, Pickering RP, Ruan WJ, et al. Prevalence of Marijuana Use Disorders in the United States Between 2001-2002 and 20122013. JAMA Psychiatry. 2015; 72:1235-42. [PubMed: 26502112]

Hasin DS, Sarvet AL, Cerdá M, Keyes KM, Stohl M, Galea S, Wall MM. US Adult Illicit Cannabis Use, Cannabis Use Disorder, and Medical Marijuana Laws: 1991-1992 to 2012-2013. JAMA Psychiatry. 2017; 74:579-88. [PubMed: 28445557]

Henningfield JE, Benowitz NL, Connolly GN, Davis RM, Gray N, Myers ML, Zeller M. Reducing tobacco addiction through tobacco product regulation. Tobacco Control. 2004; 13:132-35. [PubMed: 15175528]

Higgins ST, Heil SH, Lussier JP. Clinical implications of reinforcement as a determinant of substance use disorders. Annual Review of Psychology. 2004; 55:431-61.

Hursh SR, Roma PG. Behavioral economics and empirical public policy. J Exp Anal Behav. 2013; 99:98-124. [PubMed: 23344991]

Johnston, LD., O’Malley, PM., Miech, RA., Bachman, JG., Schulenberg, JE. Overview, Key Findings on Adolescent Drug Use. Ann Arbor: Institute for Social Research, The University of Michigan; 2015. Monitoring the Future national results on drug use: 1975-2014.

Keyes KM, Wall M, Cerda M, Schulenberg J, O’Malley PM, Galea S, Feng T, Hasin DS. How does state marijuana policy affect US youth? Medical marijuana laws, marijuana use and perceived harmfulness: 1991-2014. 2016 Addiction:n/a-n/a.

Kilmer B. Policy designs for cannabis legalization: starting with the eight Ps. Am J Drug Alcohol Abuse. 2014; 40:259-61. [PubMed: 24853283]

King KM, Chassin L. A prospective study of the effects of age of initiation of alcohol and drug use on young adult substance dependence. J Stud Alcohol Drugs. 2007; 68:256-65. [PubMed: 17286344]

Kollath-Cattano C, Abad-Vivero EN, Mejia R, Perez-Hernandez R, Sargent JD, Thrasher JF. Portrayals of character smoking and drinking in Argentine-, Mexican- and US-produced films. Prev Med. 2016; 90:143-7. [PubMed: 27404576]

Komro, KA., O’Mara, RJ., Wagenaar, AC. Perspectives from Public Health. In: Wagenaar, AC., Burris, S., editors. Public health law research: Theory and methods. 1. John Wiley \& Sons; 2013. p. 49-86.

Kuntsche E, Kuendig H, Gmel G. Alcohol outlet density, perceived availability and adolescent alcohol use: a multilevel structural equation model. Journal of Epidemiology and Community Health. 2008; 62:811-16. [PubMed: 18701732]

Landman A, Cortese DK, Glantz S. Tobacco industry sociological programs to influence public beliefs about smoking. Social Science \& Medicine. 2008; 66:970-81. [PubMed: 18164524] 
Loflin M, Earleywine M. A new method of cannabis ingestion: the dangers of dabs? Addict Behav. 2014; 39:1430-3. [PubMed: 24930049]

Lopez-Quintero C, Pérez de los Cobos J, Hasin DS, Okuda M, Wang S, Grant BF, Blanco C. Probability and predictors of transition from first use to dependence on nicotine, alcohol, cannabis, and cocaine: results of the National Epidemiologic Survey on Alcohol and Related Conditions (NESARC). Drug Alcohol Depend. 2011; 115:120-30. [PubMed: 21145178]

Lovato C, Watts A, Stead LF. Impact of tobacco advertising and promotion on increasing adolescent smoking behaviours. Cochrane Database of Systematic Reviews. 2011

Mair C, Freisthler B, Ponicki WR, Gaidus A. The impacts of marijuana dispensary density and neighborhood ecology on marijuana abuse and dependence. Drug Alcohol Depend. 2015; 154:111-6. [PubMed: 26154479]

McCrady, BS., Epstein, EE. Addictions: a comprehensive guidebook. Second. Oxford University Press; Oxford, New York: 2013.

Miech RA, Johnston L, O’Malley PM, Bachman JG, Schulenberg J, Patrick ME. Trends in use of marijuana and attitudes toward marijuana among youth before and after decriminalization: the case of California 2007-2013. Int J Drug Policy. 2015; 26:336-44. [PubMed: 25662893]

Morean ME, Kong G, Camenga DR, Cavallo DA, Carroll KM, Pittman B, Krishnan-Sarin S. Contingency management improves smoking cessation treatment outcomes among highly impulsive adolescent smokers relative to cognitive behavioral therapy. Addictive Behaviors. 2015; 42:86-90. [PubMed: 25462659]

Mosher JF, Johnsson D. Flavored alcoholic beverages: an international marketing campaign that targets youth. J Public Health Policy. 2005; 26:326-42. [PubMed: 16167560]

National Institutes of Health. Marijuana and Cannabinoids: A Neuroscience Research Summit, Marijuana and Cannabinoids: A Neuroscience Research Summit. National Institutes of Health; Bethesda, MD: 2016.

Pacek LR, Mauro PM, Martins SS. Perceived risk of regular cannabis use in the United States from 2002 to 2012: Differences by sex, age, and race/ethnicity. Drug and Alcohol Dependence. 2015; 149:232-44. [PubMed: 25735467]

Pacula RL, Hunt P, Boustead A. Words Can Be Deceiving: A Review of Variation Among Legally Effective Medical Marijuana Laws in the United States. J Drug Policy Anal. 2014a; 7:1-19. [PubMed: 25657828]

Pacula RL, Kilmer B, Wagenaar AC, Chaloupka FJ, Caulkins JP. Developing public health regulations for marijuana: lessons from alcohol and tobacco. Am J Public Health. 2014b; 104:1021-8. [PubMed: 24825201]

Pacula RL, Lundberg R. Why Changes in Price Matter When Thinking About Marijuana Policy: A Review of the Literature on the Elasticity of Demand. Public Health Rev. 2014; 35:1-18. [PubMed: 25642015]

Pacula RL, Powell D, Heaton P, Sevigny EL. Assessing the effects of medical marijuana laws on marijuana use: the devil is in the details. J Policy Anal Manage. 2015; 34:7-31. [PubMed: 25558490]

Pacula RL, Sevigny EL. Marijuana liberalization policies: why we can't learn much from policy still in motion. J Policy Anal Manage. 2014; 33:212-21. [PubMed: 24358530]

Palamar JJ, Ompad DC, Petkova E. Correlates of intentions to use cannabis among US high school seniors in the case of cannabis legalization. Int J Drug Policy. 2014; 25:424-35. [PubMed: 24589410]

Pechmann C, Knight SJ. An Experimental Investigation of the Joint Effects of Advertising and Peers on Adolescents' Beliefs and Intentions about Cigarette Consumption. Journal of Consumer Research. 2002; 29:5-19.

Perkonigg A, Goodwin RD, Fiedler A, Behrendt S, Beesdo K, Lieb R, Wittchen HU. The natural course of cannabis use, abuse and dependence during the first decades of life. Addiction. 2008; 103:439-49. [PubMed: 18269364]

Printz C. TCORS set to support the FDA's regulatory role: Program designed to generate tobaccorelated research to inform policy. Cancer. 2014; 120:771-72. [PubMed: 24595674] 
ProCon.org. 28 Legal Medical Marijuana States plus DC. 2017. March 31, 2017 ed, http:// medicalmarijuana.procon.org/view.resource.php?resourceID $=000881$

Raber JC, Elzinga S, Kaplan C. Understanding dabs: contamination concerns of cannabis concentrates and cannabinoid transfer during the act of dabbing. J Toxicol Sci. 2015; 40:797-803. [PubMed: 26558460]

Ramesh D, Haney M, Cooper ZD. Marijuana's dose-dependent effects in daily marijuana smokers. Exp Clin Psychopharmacol. 2013; 21:287-93. [PubMed: 23937597]

Reitzel LR, Cromley EK, Li Y, Cao Y, Dela Mater R, Mazas CA, Cofta-Woerpel L, Cinciripini PM, Wetter DW. The effect of tobacco outlet density and proximity on smoking cessation. Am J Public Health. 2011; 101:315-20. [PubMed: 21164089]

Richter KP, Levy S. Big marijuana-lessons from big tobacco. N Engl J Med. 2014; 371:399-401. [PubMed: 24918955]

Rocky Mountain High Intensity Drug Trafficking Area. The Legalization of Marijuana in Colorado. The Impact. 2016

Roditis ML, Delucchi K, Chang A, Halpern-Felsher B. Perceptions of social norms and exposure to pro-marijuana messages are associated with adolescent marijuana use. Prev Med. 2016; 93:17176. [PubMed: 27746339]

Schmidt LA, Jacobs LM, Spetz J. Young People's More Permissive Views About Marijuana: Local Impact of State Laws or National Trend? American Journal of Public Health. 2016:e1-e6.

Schuermeyer J, Salomonsen-Sautel S, Price RK, Balan S, Thurstone C, Min SJ, Sakai JT. Temporal trends in marijuana attitudes, availability and use in Colorado compared to non-medical marijuana states: 2003-11. Drug Alcohol Depend. 2014; 140:145-55. [PubMed: 24837585]

Scribner RA, Cohen DA, Fisher W. Evidence of a Structural Effect for Alcohol Outlet Density: A Multilevel Analysis. Alcoholism: Clinical and Experimental Research. 2000; 24:188-95.

Sevigny EL, Pacula RL, Heaton P. The effects of medical marijuana laws on potency. Int J Drug Policy. 2014; 25:308-19. [PubMed: 24502887]

Skinner ML, Haggerty KP, Casey-Goldstein M, Thompson RW, Buddenberg L, Mason WA. Focus Groups of Parents and Teens Help Develop Messages to Prevent Early Marijuana Use in the Context of Legal Retail Sales. Subst Use Misuse. 2016:1-8.

Swift W, Coffey C, Carlin JB, Degenhardt L, Patton GC. Adolescent cannabis users at 24 years: trajectories to regular weekly use and dependence in young adulthood. Addiction. 2008; 103:1361-70. [PubMed: 18855826]

Tashkin DP, Baldwin GC, Sarafian T, Dubinett S, Roth MD. Respiratory and immunologic consequences of marijuana smoking. Journal of Clinical Pharmacology. 2002; 42:71S-81S. [PubMed: 12412839]

van der Pol P, Liebregts N, Brunt T, van Amsterdam J, de Graaf R, Korf DJ, van den Brink W, van Laar M. Cross-sectional and prospective relation of cannabis potency, dosing and smoking behaviour with cannabis dependence: an ecological study. Addiction. 2014; 109:1101-9. [PubMed: 24628797]

van der Pol P, Liebregts N, de Graaf R, Korf DJ, van den Brink W, van Laar M. Validation of selfreported cannabis dose and potency: an ecological study. Addiction. 2013; 108:1801-8. [PubMed: 23627816]

Vandrey R, Herrmann ES, Mitchell JM, Bigelow GE, Flegel R, LoDico C, Cone EJ. Pharmacokinetic Profile of Oral Cannabis in Humans: Blood and Oral Fluid Disposition and Relation to Pharmacodynamic Outcomes. J Anal Toxicol. 2017:1-17.

Vandrey R, Raber JC, Raber ME, Douglass B, Miller C, Bonn-Miller MO. Cannabinoid Dose and Label Accuracy in Edible Medical Cannabis Products. JAMA. 2015; 313:2491-3. [PubMed: 26103034]

Vandrey, RG., Budney, AJ. Cannabis Use Disorders. In: Stolerman, IP., Price, LH., editors. Encyclopedia of Psychopharmacology. Springer-Verlag; Berlin Heidelberg: 2015. p. 336-41.

Volkow ND, Baler RD, Compton WM, Weiss SR. Adverse health effects of marijuana use. New England Journal of Medicine. 2014; 370:2219-27. [PubMed: 24897085] 
Wall MM, Poh E, Cerda M, Keyes KM, Galea S, Hasin DS. Adolescent marijuana use from 2002 to 2008: higher in states with medical marijuana laws, cause still unclear. Ann Epidemiol. 2011; 21:714-6. [PubMed: 21820632]

Weiss SR, Howlett KD, Baler RD. Building smart cannabis policy from the science up. Int J Drug Policy. 2017

Wen H, Hockenberry JM, Cummings JR. The effect of medical marijuana laws on adolescent and adult use of marijuana, alcohol, and other substances. J Health Econ. 2015; 42:64-80. [PubMed: 25863001]

Whiting PF, Wolff RF, Deshpande S, Di Nisio M, Duffy S, Hernandez AV, Keurentjes JC, Lang S, Misso K, et al. Cannabinoids for medical use: a systematic review and meta-analysis. JAMA. 2015; 313:2456-73. [PubMed: 26103030] 


\section{Highlights}

- Legal cannabis law provisions may differentially impact risk of cannabis addiction

- Such laws may influence cannabis pharmacology, access, and culture

- Known factors that contribute to addiction should guide cannabis policy design

- Increased funding is needed to bolster cannabis regulatory science 